\title{
Evolución cognitiva y conocimiento reflexivo. La teoría de los órdenes sociales de Emanuel Adler y la elección de la Convención Nacional Constituyente en Uruguay (1916) ${ }^{1}$
}

\section{Cognitive Evolution and Reflexive Knowledge. The Theory of the Social Orders of Emanuel Adler and the Election of the National Constituent Convention in Uruguay (1916)}

\author{
Adolfo Garcé García y Santos ${ }^{2}$ \\ Universidad de la República (Uruguay) \\ Esteban García Ortiz ${ }^{3}$ \\ Universidad de la República (Uruguay)
}

Recibido: 27-12-18

Aprobado: 17-06-19

\section{Resumen}

El 30 de julio de 1916 se eligieron los representantes para la Convención encargada de elaborar la segunda constitución uruguaya que fijó las reglas de la naciente democracia. En esta elección se utilizaron por primera vez el voto secreto y una versión inédita de representación proporcional. Para explicar por qué se usaron esas reglas y no otras, se utiliza la teoría de los órdenes sociales de Emanuel Adler. Las nuevas reglas recogen en el plano institucional la evolución

\footnotetext{
${ }^{1}$ Agradecemos los generosos comentarios de Emanuel Adler a la primera versión de este texto.

2 (adolfo.garce@cienciassociales.edu.uy) Doctor en Ciencia Política, Profesor Titular del Departamento de Ciencia Política, Facultad de Ciencias Sociales. Algunas de sus publicaciones destacadas: "Hacia una teoría ideacional de la difusión institucional. La adopción y adaptación del presidencialismo en América Latina durante el siglo XIX". Revista Española de Ciencia Política, 44(1), 13-41, 2017 y el libro Donde hubo fuego. El proceso de adaptación del MLN-Tupamaros a la legalidad y a la competencia electoral (1985-2004), Fin de Siglo, Montevideo, 2006.

${ }^{3}$ (elgarciaesteban@gmail.com) Maestrando en Ciencia Política, Becario del Fondo Clemente Estable en el Departamento de Ciencia Política, Facultad de Ciencias Sociales. Su última publicación: "El lado oscuro del éxito: los proyectos del Poder Ejecutivo no votados por el Parlamento uruguayo (2005-2010)”. Revista Uruguaya de Ciencia Política, 26 (1): 175-196, 2017.
} 
cognitiva de caudillos y doctores, los protagonistas centrales de la comunidad de práctica democrática uruguaya. Los caudillos fueron aprendiendo en la práctica, por ensayo y error, a competir por el poder pero también a pactar. Los doctores, a partir de esas prácticas pero también de las teorías que circulaban en la época, aportaron el conocimiento reflexivo que recogieron las nuevas normas. De todos modos, no es posible comprender la trayectoria doméstica sin tomar en cuenta la influencia de procesos exógenos. La Convención de Buenos Aires (1870-1873) y la Ley Sáenz-Peña (1912) tuvieron un impacto profundo en Uruguay.

Palabras-clave: Ideas, evolución cognitiva, comunidades de práctica, cambio constitucional, Uruguay.

\begin{abstract}
The second Uruguayan constitution set the rules for the emerging democracy and was conceived at a convention composed by a set of representatives that were elected on July 30, 1916. It was for this election that the secret ballot was used for the first time, as well as a new version of proportional representation. To explain why these rules and not others were used, this paper resorts to Emanuel Adler's theory of social orders. At the institutional level, the new rules collect the cognitive evolution of caudillos and doctores, the main protagonists of the Uruguayan democratic practice community. The caudillos learned by doing, on the spur of the moment and by trial and error, to compete for power but also to find agreements. The doctores, both through political practice but also from the theories that circulated at the time, contributed the reflective knowledge that those new rules collected. Nevertheless, it is not possible to understand these developments without taking into account the influences of exogenous processes. The Convention of Buenos Aires (1870-1873) and the Sáenz-Peña Electoral Law (1912) namely had a profound impact on Uruguay.
\end{abstract}

Key-words: Ideas, cognitive evolution, communities of practice, constitutional change, Uruguay.

\title{
1. La democracia uruguaya como comunidad de práctica: ideas, discursos, evolución cognitiva y dinámica institucional
}

El 30 de julio de 1916 es una fecha clave en el proceso de instauración de la democracia uruguaya. Ese día se celebró la elección de delegados a la Convención Nacional Constituyente (CNC) que elaboró la segunda constitución (vigente entre 1919 y 1934). En esa elección el batllismo (sector mayoritario del Partido Colorado) fue derrotado sorpresivamente. La derrota del gobierno 
generó una oportunidad para la negociación con la oposición respecto al contenido de las nuevas reglas de juego de la naciente poliarquía. La Ley $\mathrm{N}^{\circ}$ 5332, aprobada en setiembre de 1915, estableció que los convencionales serían electos por primera vez en la historia electoral del país mediante voto secreto, y estableció una modalidad atenuada y novedosa de representación proporcional: $3 /{ }_{5}$ para la mayoría, $2 / 5$ para la minoría distribuidos proporcionalmente.

Se ha escrito mucho sobre el proceso de negociación realizado en el marco de la CNC y en la "Comisión de los Ocho" y sobre las importantes innovaciones institucionales consagradas en la nueva Constitución (Martínez 1964, Vanger 2009, Corbo 2016, Buquet 2016, Lanzaro 2018) ${ }^{4}$. Sin embargo, se ha estudiado menos sistemáticamente el largo debate público que precedió a su instalación. La investigación del proceso de convocatoria a la $\mathrm{CNC}$ y de elaboración de las reglas de elección de convencionales ofrece respuestas novedosas a preguntas importantes que no han tenido, hasta la fecha, respuestas precisas. ¿Por qué el gobierno luego de derrotar categóricamente al ejército del Partido Nacional incluyó, entre las cláusulas de la Paz de Aceguá (1904), la propuesta de reforma constitucional que era la principal reivindicación histórica de los vencidos? ¿Por qué, para reformar la constitución, se optó por convocar a una Convención Constituyente en vez de recorrer el camino previsto por la Constitución de 1830? ¿Por qué el batllismo, que estaba doctrinariamente en contra del voto secreto y que tenía mayoría en el Parlamento, lo aceptó como regla para la elección de constituyentes en 1915 ? ¿Cómo fue el proceso de elaboración de la regla de representación proporcional atenuada que se terminó utilizando en la ley que convocó a elegir convencionales? En suma: ¿por qué se usaron esas reglas y no otras?

Para responder estas preguntas adoptamos un enfoque teórico diferente al que ofrecen habitualmente tanto la historiografía uruguaya como la literatura sobre cambio constitucional. A la hora de explicar la instauración de la democracia la Historia Política nacional pone el acento en la dinámica de competencia y cooperación entre colorados y blancos (de la guerra a la “coparticipación"), y en el papel de los "caudillos" en el liderazgo de los partidos (Castellanos y Pérez Antón 1981, Corbo 2019). La literatura sobre cambio constitucional, por su parte, asume que los cálculos estratégicos de los actores juegan un papel decisivo (Negretto 2013). Siguiendo esta pista

\footnotetext{
${ }^{4}$ La Constitución de 1918, aunque tuvo una vida efímera (fue reformada en 1934), tiene un lugar muy importante en la historia del constitucionalismo uruguayo: se institucionalizó la democracia de masas por medio del sufragio universal masculino y del voto secreto; se mejoraron los mecanismos de inclusión de las minorías por medio de la representación proporcional para la Cámara de Representantes; se atenuó de modo sustancial el poder presidencial y se fortaleció concomitantemente el Poder Legislativo; se reformaron y ampliaron las estructuras estatales dando rango constitucional al "dominio industrial y comercial del Estado"; llevando un paso más lejos el proceso de secularización iniciado años antes, se sancionó la "libertad de cultos". Remitimos al Número Temático "La constitución uruguaya de 1918 y el constitucionalismo latinoamericano" de la Revista Uruguaya de Ciencia Politica coordinado por Jorge Lanzaro (2018).
} 
teórica, Buquet y Moraes (2018) propusieron una persuasiva explicación de la construcción de la democracia uruguaya a través de un ejercicio de narrativa analítica que modeliza las interacciones estratégicas entre los actores.

Ambas interpretaciones ayudan a entender el proceso que nos interesa reconstruir. En primer lugar, aunque algunas lecturas remiten la democratización al mérito de un solo actor (para algunos el batllismo, para otros el nacionalismo), la democracia uruguaya es hija del largo proceso de construcción de acuerdos entre los partidos en pugna, que tiene en la Paz de Abril (1872) un punto de inflexión definitivo. En segundo lugar, también está muy claro que los partidos uruguayos se estructuraron sobre las adhesiones caudillistas como ha sido largamente dicho y explicado por la Historiografía desde Pivel Devoto en adelante. Finalmente, va de suyo que los caudillos tenían la conquista del poder como objetivo central y que, por ende, estaban muy atentos a las consecuencias distributivas de las reglas institucionales en debate.

A pesar de sus méritos, hay aspectos del proceso de instauración de la democracia que estos enfoques no iluminan adecuadamente. El énfasis en los caudillos puede oscurecer la influencia de otra clase de liderazgos políticos. La insistencia en el papel de los intereses puede eclipsar el de las ideas, la otra cara de la moneda. Los llamados "doctores" (universitarios, en general, abogados, en particular) desempeñaron un papel clave en la formulación y diseminación de ideas (principios, valores, creencias causales, soluciones institucionales) que, articulándose con las ideas e intereses de los caudillos, alumbraron el camino del cambio institucional. Además, como veremos, la peripecia de las ideas en Uruguay (formulación, circulación e impacto) no puede ser explicada sin trascender las fronteras nacionales. El proceso político y doctrinario en la otra orilla del Río de la Plata (especialmente en Buenos Aires) influyó decisivamente en la trayectoria institucional estudiada.

$$
* * *
$$

Para captar el papel de los doctores en la dinámica institucional nos apoyaremos en la teoría de los órdenes sociales elaborada por Emanuel Adler (Adler 2019, Adler 1997), que forma parte del "practice turn" en Relaciones Internacionales (Adler y Pouliot 2011). Según Adler, para funcionar, los órdenes sociales no sólo requieren instituciones sino también prácticas. ${ }^{5}$ Tanto las instituciones como las prácticas reflejan la evolución cognitiva, es decir, los aprendizajes que van realizando las sociedades. El aprendizaje no es ni inexorable ni definitivo. Los órdenes sociales combinan cambio y estabilidad. Sobre la marcha, pragmáticamente, se va generando un conocimiento de fondo ("background knowledge"), que informa las prácticas y es selectivamente

\footnotetext{
${ }^{5}$ La distinción entre conductas, acciones y prácticas puede leerse en Adler y Pouliot (2011: 6).
} 
retenido en las instituciones. Este conocimiento, en parte tácito, en parte reflexivo, es generado por las comunidades de práctica. Adler las define como "comunidades de personas que se dedican regularmente a una actividad en común que encarna el conocimiento que la comunidad desarrolla, comparte y mantiene". ${ }^{6}$ El conocimiento de fondo "dota a los practicantes de un sentido de empresa conjunta" en permanente proceso de renegociación ${ }^{7}$.

El enfoque de Adler tiene importantes puntos de contacto con la "sociología reflexiva" de Pierre Bourdieu. ${ }^{8}$ Ambas teorías se caracterizan por su alto nivel de abstracción. Ambos enfoques son relacionales y enfatizan la importancia de las prácticas. Los dos buscan superar oposiciones clásicas en la teoría social (v.g. materia objetiva versus significados intersubjetivos, ideas versus intereses, cambio versus estabilidad, agencia versus estructura). Sin embargo, el propio Adler ha explicado que su teoría está más cerca del pragmatismo norteamericano que de la filosofía de Bourdieu: "Bourdieu's inspired-practice theory and pragmatist-action theroy are both pillars of the "practice turn" (...). While I have profited from both sets of theory, I find pragmatism more useful" (Adler 2019: 121). Apartándose de Bourdieu, al elaborar su teoría de la evolución cognitiva, Adler sustituye los conceptos de habitus y campo respectivamente por los de práctica y comunidad de práctica (2019:18-19). Estos desplazamientos conceptuales le permiten, entre otras innovaciones, poner un énfasis mayor todavía en el cambio creativo, en la importancia del aprendizaje y en el papel del conocimiento reflexivo. ${ }^{9}$ Es, precisamente, este mayor énfasis en el aprendizaje y el conocimiento reflexivo lo que nos inclinan a utilizar la teoría de Adler.

Caudillos y doctores fueron actores decisivos en la comunidad de práctica democrática uruguaya. Los caracterizó un "sentido de empresa conjunta".

\footnotetext{
${ }^{6}$ En términos de Adler y Pouliot: "Communities of practice are intersubjective social structures that constitute the normative and epistemic ground for action, but they are also agents, made up of real people, who (...) affect political, economic, and social events" (2011: 17).

Aunque fue formulada en el campo de las Relaciones Internacionales, esta teoría puede ser aplicada a otros "órdenes sociales" (Adler 2019). El propio Adler, en la conferencia inaugural del 9no Congreso de ALACIP en Montevideo publicada en la Revista Uruguaya de Ciencia Política, aplicó esta teoría a la construcción de la democracia uruguaya. En esa oportunidad definió a Uruguay como una "comunidad de práctica democrática". Los uruguayos, argumentó, "se sienten diferentes (...) debido a sus prácticas democráticas (...). Uruguay se caracteriza no solamente por sus instituciones políticas y sociales relativamente fuertes, sino también por las prácticas liberales basadas en el debate, el compromiso, el consenso, y la inclusión, esta última no solamente de diversos sectores sino también de la oposición. A diferencia de otros pueblos latinoamericanos que se autodefinen como nación, los uruguayos se auto-definen más que nada como república”. Esta comunidad de práctica, según Adler, fue acumulando conocimiento a partir de sus propios fracasos (2018).

${ }^{8}$ Bourdieu es el sociólogo contemporáneo más influyente. Una excelente aproximación a su teoría puede leerse en (Bourdieu y Wacquant 2005).

${ }^{9}$ El conocimiento reflexivo, derivado de la práctica, y selectivamente retenido en las instituciones, es una clave esencial de la teoría de Adler: "A greater emphasis on the reflexive than on tacit quality of background knowledge characterizes cognitive evolution theory and differentiates it from other practice-based IR theories" (Adler 2019:111).
} 
Tenían en común la pasión por los asuntos públicos y la ambición por liderar los destinos de la nueva república. Aunque, todavía es poco lo que se sabe sobre la intercomunicación entre ambos, puede afirmarse que caudillos y doctores compartieron la estructura de conducción de blancos y colorados (Pérez Antón 2017a). Compitiendo y cooperando, aprendiendo por "ensayo y error", tomando nota de las lecciones de sus propias prácticas (la labor de gobierno tanto en el Ejecutivo como en el Legislativo, la lucha por el poder tanto dentro como fuera de lo establecido en la Constitución), contribuyeron a generar los cambios en el conocimiento de fondo que hicieron posible nuevas prácticas (v.g. la inclusión de la oposición por medio de la "coparticipación") y nuevas instituciones políticas (en especial, las sucesivas leyes de representación proporcional desde fines del siglo XIX, la incorporación del voto secreto a partir de 1916, y la atenuación del poder presidencial en la Constitución de 1918).

Los caudillos fueron líderes decisivos. En torno a ellos, a lo largo del siglo XIX, se vertebraron los partidos modernos. En última instancia, lo que distingue al caudillo es la profundidad y naturaleza del vínculo con sus apoyos societales. El lazo entre el caudillo y su gente es muy potente. Para decirlo en los términos de Pérez Antón: "la conducción caudillista admite variaciones críticas, lo que permite reconocer caudillos en múltiples contextos económicos y sociales, pero, principalmente, en marcos constitucionales diversos e incluso antagónicos. El elemento constante, la piedra de toque de dicha conducción se encuentra, (...), en el diálogo inmediato y en doble dirección: los mensajes del dirigente a un colectivo popular y de ese colectivo popular al dirigente" (Pérez Antón 2017b: 165-166).

Para dar cuenta de la naturaleza del liderazgo caudillista hay que tomar en cuenta que, como advirtiera Real de Azúa, los únicos modos de legitimidad disponibles luego de las guerras de independencia eran la personal y la retributiva: "de su combinación nace la fuerza del fenómeno caudillista en términos de legitimación (1969: 111). Los caudillos incorporaron a las masas populares, distribuyeron recursos, protegieron a sus secuentes, generaron identidades, construyeron ciudadanía. En ausencia de un sentimiento nacional extendido, operaron como "patrias subjetivas". Los caudillos, además, jugaron un papel muy importante en la dinámica de las ideas. En palabras de Pérez Antón: "El caudillo se encarga de expresar-proponer las grandes orientaciones y cuidar las condiciones principales de la preservación del partido y de desarrollarse y competir con posibilidades de éxito" (2017a: 189).

Sin embargo, el aprendizaje político protagonizado por los caudillos fue favorecido y complementado por su interacción con los doctores. Al menos hasta mediados del siglo XX los abogados, en particular, fueron actores de primer orden en la tarea legislativa y en la gestión cotidiana de los sucesivos gobiernos (Pérez Antón 2017a: 189, Delio 2007: 18). Pero fracasaron 
sistemáticamente en sus intentos de desplazar a los caudillos y terminaron subordinándose a ellos. Desde todas las tribunas a su alcance, los doctores insistieron en reclamar el imperio de la ley y una política estructurada sobre principios y valores, y no en torno a lealtades personales (Ardao 1950, Moraes 1995, Garcé 2000, Castiglia 2004, Rilla 2008).). Definieron problemas: la inestabilidad política, la violación de la constitución, el fraude electoral, la exclusión de las minorías (Oddone 1956, Gallardo 2003). Y se esforzaron en proponer soluciones concretas: reforma constitucional, padrón electoral, voto secreto, representación proporcional. Ellos también, como los caudillos, fueron aprendiendo sobre la marcha, pragmáticamente. Aprendieron que las "divisas" (colorada y blanca) no podían ser suprimidas, y que el cambio político (la mejora de las instituciones) debía construirse con los caudillos y no contra ellos.

En tanto protagonistas de la dinámica política cotidiana, en la práctica, caudillos y doctores participaron activamente en la lucha por el apoyo popular y en "mercado" de las ideas ${ }^{10}$. Pero las semejanzas no deberían impedirnos reconocer las diferencias. Si lo que distingue al caudillo es su idoneidad para cumplir las funciones de representación, el rasgo principal del doctor es su capacidad para, sobre la base del conocimiento especializado derivado de su formación profesional, elaborar respuestas a los problemas identificados. El doctor, especialmente durante el siglo XIX, casi siempre abogado de formación, es un ideólogo y un experto, para utilizar la distinción popularizada por Bobbio. En tanto ideólogos, los doctores proporcionaron "principios-guía", es decir, ideas generales respecto a fines: principios, valores, ideales, concepciones del mundo. En tanto expertos, ofrecieron medios concretos para alcanzar los fines deseados: leyes, instituciones, políticas públicas. No es posible entender el camino hacia la CNC y, por tanto, hacia la democracia en Uruguay, sin dar cuenta del aporte de este conocimiento reflexivo elaborado pragmáticamente por los doctores en el fragor de los conflictos políticos de la época.

$$
* * *
$$

Para reconstruir el largo proceso de elaboración de la propuesta de convocar a una Convención Nacional Constituyente y de las reglas de elección de los convencionales se recorrerá la secuencia analítica siguiente. En la sección 2 se presenta la información sobre cómo se fue construyendo la propuesta, finalmente aprobada, de modificar el procedimiento de reforma constitucional previsto en 1830 para hacer posible la convocatoria a una Convención Constituyente. En la sección 3 se analiza de qué modo se terminó adoptando el voto secreto y la

${ }^{10}$ La literatura sobre los intelectuales suele tener un sesgo "intelectualista". Esto es: tiende a asignar a los intelectuales un protagonismo especial en la generación y diseminación de ideas.

Araucaria. Revista Iberoamericana de Filosofia, Política, Humanidades y Relaciones Internacionales, año $21, \mathrm{n}^{\circ} 42$. Segundo semestre de 2019. Pp. 243-276. ISSN 1575-6823 e-ISSN 2340-2199 doi: 10.12795/araucaria.2019.i42.11 
representación proporcional atenuada como regla para elegir convencionales. En cada una de estas etapas del análisis se buscará distinguir las voces de los caudillos de las de los doctores. Asimismo, se prestará especial atención a rastrear hasta qué punto y de qué modo concreto los aportes "doctos" fueron siendo incorporados en la agenda y en las propuestas concretas reformistas. Finalmente, en la sección 4 se sintetiza el proceso y se presentan las principales implicancias teóricas de los hallazgos.

\section{La Convención Constituyente como mecanismo de reforma}

La primera pregunta que queremos contestar refiere al origen del mecanismo utilizado para reformar la constitución, es decir, a la convocatoria de una Convención Nacional Constituyente. ¿De dónde salió esta idea? La respuesta es menos simple de lo que parece. Es cierto que el mecanismo estaba previsto en la Constitución de 1830. Sin embargo, de acuerdo al artículo 159 de dicho texto, una "grande asamblea", "compuesta de número doble de Senadores y Representantes", debía ser convocada solamente para modificar la "forma constitucional" y no para innovaciones menos radicales como las consagradas en la Constitución de 1918.

La Constitución de 1830 no detalla a qué se refiere exactamente con la expresión "forma constitucional". De todos modos, como explicara Barbagelata, ha prevalecido entre los constitucionalistas el punto de vista de Santiago Vázquez, uno de los constituyentes más activos, que durante el debate argumentó que el sentido de este artículo quedaría más claro diciendo: "la forma constitucional comprendida en las secciones $1^{\mathrm{a}}$ y $3^{\mathrm{a}}$ (1978:15). Estas dos secciones hacen referencia a los principios más generales de la "forma" constitucional (v.g: Uruguay como Estado independiente, que adopta "para su gobierno la forma representativa republicana" y delega la "soberanía" a tres "Altos Poderes, Legislativo, Ejecutivo y Judicial”). En suma: la expresión "forma constitucional" debe ser entendida como la definición a favor de la independencia nacional y de la forma democrático-republicana de gobierno ${ }^{11}$.

El procedimiento normal de reforma constitucional se consagró en los artículos 152 a 158. De acuerdo al artículo 152 de la Constitución de 1830 le correspondía al Poder Legislativo reformar la Constitución. Este mecanismo requería la participación de tres legislaturas sucesivas: la primera debía declarar de interés nacional la revisión de la Constitución (por un tercio de cada cámara, y luego, por dos tercios de las dos cámaras reunidas), la segunda debía

${ }^{11}$ Los profesores de Derecho Constitucional José Korzeniak y Ruben Correa Freitas, consultados sobre el punto, comparten esta interpretación. Dejamos constancia de nuestro agradecimiento hacia ambos. 
considerar las "reformas, variaciones o adiciones" (los legisladores debían ser "autorizados con poderes especiales de sus comitentes" por un tercio de ambas cámaras), y la tercera sería la encargada de discutir las enmiendas y sancionarlas por el procedimiento legislativo normal (De la Bandera 1969: P.XVI).

La nueva constitución surgió de una Asamblea Constituyente. Sin embargo, no tiene una "forma constitucional" distinta. Uruguay siguió siendo una república presidencialista independiente con tres "Altos Poderes" separados. Por tanto, el procedimiento utilizado para reformar la constitución no fue el previsto en 1830. En verdad, se recorrió un camino similar al de la "grande Asamblea" pero para consagrar modificaciones institucionales de otra índole. Para eso, buscando evitar violar la constitución, la elite política modificó, mediante el procedimiento normal (el de las tres legislaturas sucesivas) el mecanismo de reforma previsto en los artículos 152 a 158. La solución fue ingeniosa. Se recorrió el camino legislativo para modificar el procedimiento de reforma constitucional. Y se utilizó la convocatoria a una "Grande Asamblea" (la CNC) para modificar la Constitución sin variar la "forma" constitucional.

La elite política fue, en términos formales, extraordinariamente cuidadosa. Mirado a la distancia, tantas precauciones sorprenden ${ }^{12}$. En verdad, si algo estaba claro en la naciente república durante el siglo XIX era que el texto constitucional se violaba sistemáticamente. Tanto los caudillos como los doctores tenían plena conciencia de hasta qué punto la vida política se apartaba de las normas constitucionales. Ambos comprendieron muy tempranamente que había que modificar las normas, pero prefirieron no violar la constitución para hacer posible estas reformas. Encontrar el camino hacia la reforma les llevó muchos años de experimentación, de debates políticos y académicos, de "ensayo y error", de evolución cognitiva para usar los términos de Adler. Intentaron en diversas oportunidades recorrer el camino legislativo. Quedó muy claro que este procedimiento, en tiempos de inestabilidad política y de altos niveles de desconfianza y fraude, era inviable. Y debatieron, desde los primeros años de vida independiente, sobre la posibilidad de consultar directamente al "soberano" mediante una Asamblea Constituyente.

\section{Arqueología del procedimiento reformista}

En su extraordinaria biografía de Alfredo Vázquez Acevedo, María Julia Ardao elaboró la más detallada reconstrucción histórica del largo camino hacia la reforma constitucional de $1917^{13}$. "El primer intento por reformar

${ }^{12}$ Una vez que se concluye que la elite política estuvo más de medio siglo discutiendo cómo reformar una constitución tan rígida como de 1830 sin violar ninguna norma se entiende mucho mejor por qué fue tan dramática la ruptura constitucional de 1933, y por qué dejó heridas tan profundas.

13 Debemos el conocimiento de este brillante antecedente a Gerardo Caetano. Accedimos al texto de María Julia Ardao gracias a la colaboración de Mónica Paz, directora de la Biblioteca del Palacio 
la Constitución -dice- fue el petitorio presentado por los militares en 1829" (1973:338). Los militares, excluidos del parlamento por iniciativa de la "escuela francesa" liderada por José Ellauri dentro de la Asamblea Constituyente (Bauzá 1887:276), se apresuraron a cuestionar esta decisión. Bauzá narró este episodio en los términos siguientes: "La agresión a sus derechos, (...), había sido tan insólita, la ingratitud para con sus servicios tan palmaria, que los militares de la Independencia al verse arrojados de la representación nacional, levantaron la voz en defensa de sus legítimos intereses vulnerados" (1887:321).

Los militares redactaron una petición dirigida a la Asamblea Constituyente. Iba firmada, entre otros, por Rivera y Lavalleja. En "lenguaje respetuoso pero enérgico" reclamaron "abrir siquiera por un término dado, el santuario de las leyes y de las magistraturas populares, a los que lo erigieron con su espada, lo consolidaron con su sangre" (Bauzá 1887: 322). La Asamblea Constituyente "rehusó oírles": "la solicitud de los militares quedó encarpetada" (Bauzá 1887: 325). La exclusión tuvo un costo muy alto:

\begin{abstract}
"Nos atrevemos a creer, que si Lavalleja hubiera sido Senador, y algunos de los militares sus amigos, diputados, no hace contra Rivera el movimiento insurreccional de 1832; del mismo modo que si Rivera y los suyos hubiesen ocupado igual posición bajo la presidencia de Oribe, otro sesgo toma la terrible contienda que nos trajo la guerra grande. Casi todos nuestros males proceden del exclusivismo (...)" (Bauzá 1887: 324).
\end{abstract}

La constitución "exclusivista" fue sancionada. Pero la necesidad de su reforma ya era evidente en los primeros años de su vigencia. En 1834 aparecieron en la prensa los primeros artículos a favor de la reforma constitucional. En 1836, en la Cámara de Representantes, Ramón Masini presentó la primera moción reformista que fue apoyada por más de la tercera parte de los representantes presentes. En ese contexto, José Ellauri, que había tenido un papel protagónico, en la Constituyente, elaboró un proyecto de reforma (Ardao 1973: 338-345). Muy poco después, en 1838, aparece la otra alternativa reformista: "en oportunidad de negociarse la paz entre Rivera y el presidente Oribe, Francisco José Muñoz propuso la reforma de la Constitución, mediante la convocatoria de una Doble Asamblea. Rivera recogió esta propuesta en el Manifiesto publicado en Durazno en 1839, redactado por Juan Bautista Alberdi. Reclamaba en él, como explica Ardao, "fortalecer el Poder Ejecutivo y organizar el gobierno municipal". Las Cámaras -agrega- aceptaron la idea y entendieron que debía hacerse mediante una Doble Asamblea" (1973: 346).

Este breve repaso ayuda a ilustrar que la reforma de la constitución formó parte de la agenda política desde la primera década de vida independiente. Todos los actores relevantes decían defender la Constitución. En mayor o

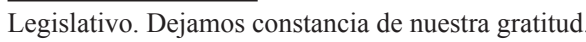

Araucaria. Revista Iberoamericana de Filosofía, Política, Humanidades y Relaciones Internacionales, año $21, \mathrm{n}^{\circ} 42$. Segundo semestre de 2019. Pp. 243-276. ISSN 1575-6823 e-ISSN 2340-2199 doi: 10.12795/araucaria.2019.i42.11 
menor medida, ninguno la respetaba. Desde el principio, además, se discutió sobre los dos caminos posibles: la vía legislativa en tres pasos sucesivos y la de la Asamblea Constituyente. Para muchos dirigentes de la época el camino de la Doble Asamblea, pese a estar previsto en la carta de 1830 para otros fines, era el más práctico. El camino de las tres legislaturas sucesivas era poco aconsejable dadas la inestabilidad política reinante y las escasas garantías del sufragio. Se insistió, por tanto, en la propuesta de una Asamblea Constituyente en 1840, 1841, 1851 y 1853. De hecho, el Triunvirato conformado poco después de la Guerra Grande llegó a convocarla (Ardao 1973: 348). Esta "Grande Asamblea" llegó a reunirse pero actuó solamente como asamblea legislativa. Se limitó a declarar, de acuerdo al artículo 153 de la Constitución, de "interés nacional" la reforma constitucional.

En cualquier caso, la cuestión de la reforma constitucional pasó a ser una prioridad en cada uno de los siguientes gobiernos. Uno de los presidentes que más enfáticamente reclamó la reforma fue Bernardo Berro. En 1863, en su Mensaje a la Asamblea Legislativa, puede leerse: “¿Qué es mejor? ¿Violar la Constitución para evitar el mal que, de observarla viene, o corregirla para suprimir el mal y esa violación?" (Ardao 1973: 349). Una década más tarde, quedó todavía más claro que la observancia de la Constitución, lejos de facilitar la paz, generaba estímulos para la guerra. En la Paz de Abril que puso fin a la Revolución de las Lanzas (1872), se consagró el principio de la coparticipación que facilitaba la participación de la minoría pero, a la vez, violaba la Constitución ${ }^{14}$. Es evidente que, por eso mismo, la coparticipación, tal como afirma María Julia Ardao, “animó de manera constante el proceso de Reforma Constitucional, a fin de adecuar el orden legal al país real" (1973: 352-353).

\section{La Cátedra de Derecho Constitucional y la generación principista}

La intensidad del debate sobre procedimientos y contenidos de la reforma siguió aumentando. La creación de la Cátedra de Derecho Constitucional en 1870 vino a darle un estímulo adicional ${ }^{15}$. Su primer catedrático fue Carlos María Ramírez. Durante su breve actuación (1871-1873) hizo una defensa encendida de la libertad (buscaba promover la "aversión a los tiranos" y el "fervor por la libertad"). Además, desde un enfoque de carácter historicista, promovió el ajuste de las normas constitucionales a las circunstancias. La Constitución de

\footnotetext{
${ }^{14}$ Según el texto constitucional de 1830 le correspondía al Presidente designar los Jefes Políticos de los departamentos del país. Dado el control que los jefes políticos ejercían sobre el proceso electoral, la designación de estas autoridades era un punto clave. En la Paz de Abril los colorados admitieron que en cuatro departamentos el Jefe Político fuera designado por el Presidente pero a propuesta del Partido Nacional (Pérez Antón 1988).

15 Se crea a iniciativa del Rector de la Universidad, Pedro Bustamante, a través de la Ley de Presupuesto (prólogo a la obra de Ramírez, p. IX y X).
} 
1830, según él, estaba "plagada de imperfecciones, deficiencias y errores". El segundo catedrático fue aún más influyente: Justino Jiménez de Aréchaga. Ocupó la Cátedra entre 1873 y 1904. Tuvo una participación realmente sobresaliente en el debate sobre cambio institucional. Su obra La libertad politica, publicada en 1884, tuvo honda repercusión dentro y fuera del país, como veremos más adelante $^{16}$. Sustituyó a Jiménez de Aréchaga el doctor Juan Andrés Ramírez.

La instalación de la Cátedra de Derecho Constitucional coincide con el ascenso de la generación principista a la que perteneció el propio Carlos María Ramírez. Para los "principistas" la reforma constitucional fue un tema absolutamente prioritario. Desde los "clubes" y la prensa los principistas hicieron referencia una y otra vez a este desafío. El artículo 15 de Programa del Club Radical decía: "El Club Radical propenderá a que el país inicie la reforma de la Constitución". En similares términos se expresaba el Club Nacional: "reconoce la conveniencia de que la Constitución de la República sea reformada, adaptándola a las exigencias de la época y a la marcha progresiva de la sociedad". En El Siglo, mientras tanto, podía leerse: "La idea de la reforma constitucional no ha nacido de tal o cual cerebro, es una aspiración unánime del pueblo, es un verdadero sentimiento nacional. (...). La reforma constitucional es una prenda de paz y de concordia, de adelanto y de engrandecimiento... (Oddone 1956: 122-123).

Seguía, de todos modos, sin poder resolverse el problema de cómo concretar la reforma. El procedimiento reformista fue objeto de extensas consideraciones en distintos ámbitos. Algunos principistas, como Agustín de Vedia, José Pedro Varela y Alfredo Vázquez Acevedo, contra lo que hubiera podido suponerse dada la insistencia en el respeto a las formas legales que los singularizó, creían que había que hacer caso omiso de las limitaciones establecidas por el constituyente en 1830 para reformar la constitución. Sostenían que las circunstancias habían cambiado entre la década del treinta y la del setenta. Argumentaban, asimismo, que el recurso al soberano era suficiente para legitimar la nueva constitución. (Ardao 1973: 361-364). Pedro y Francisco Bauzá, desde una tradición política en muchos sentidos opuesta al "principismo", coincidieron también. Según ellos, de seguirse el procedimiento constitucional, “jamás podremos reformar la Constitución" (Ardao 1973: 365).

\footnotetext{
${ }^{16}$ Justino Jiménez de Aréchaga nació en 1850 y murió en 1904. Asumió interinamente la Cátedra de Derecho Constitucional en 1873, y por concurso el año siguiente. Desde esta posición continuó los planes de estudio de su antecesor, Carlos María Ramírez, pero centrándose especialmente en el estudio de las teorías sobre separación de poderes del Estado, los gobiernos municipales y los regímenes electorales. En octubre de 1884 fue destituido de su cargo acusado por el diario El Partido Colorado de hacer propaganda subversiva en el aula. En 1887 fue reintegrado a su cargo, en el que permaneció -con interrupciones motivadas por problemas de salud- hasta su muerte. Fue uno de los fundadores del Partido Constitucional en 1880, y por el Partido Nacional fue representante por Flores (1897-1898), integrante del Consejo de Estado de 1898 y Senador de la República (1898-1901). Ver: Diez de Medina (1994: 257-261), Oddone y Paris (2010a y 2010b), Delio (2007) y Gallardo (2018).
} 
Nace la solución "mixta”

Poco a poco fue naciendo una solución "mixta". El debate sobre el procedimiento reformista se reinició en el Parlamento en 1879, una vez restablecido el régimen constitucional interrumpido en 1875. Se instaló una Comisión Especial de 15 miembros que, durante un año, debatió el problema de la reforma. De ella surgieron dos informes, uno en mayoría y otro en minoría. El informe en mayoría es especialmente relevante porque, en él, aparece por primera vez en el parlamento la propuesta de modificar el procedimiento de la reforma constitucional mediante el mecanismo previsto en los artículos 153 a 158. Se recorrería el camino de las tres legislaturas para convocar a una Asamblea ad-hoc que promulgaría las reformas constitucionales (Ardao 385386).

Entre 1879, cuando se esbozó por primera vez este camino "mixto", y 1912, cuando terminó de aprobarse el nuevo mecanismo de reforma, el debate reformista conoció todo tipo de peripecias políticas y de planteos contrapuestos. El vínculo entre reforma constitucional y estabilidad política se fue haciendo cada vez más nítido: la inestabilidad política presionaba a favor de la reforma pero, al mismo tiempo, dado el requisito de las tres legislaturas sucesivas, la volvía virtualmente imposible. Aunque no llegó a generar ninguna decisión vinculante, un hito especialmente relevante de este proceso fue la convocatoria en 1903, en el Ateneo de Montevideo, de un Congreso Revisionista de la Constitución. Fueron convocados todos los actores que habían participado, durante los años anteriores, en la conversación sobre reforma constitucional, desde José Batlle y Ordóñez a Justino Jiménez de Aréchaga. El Congreso Revisionista de la Constitución fue un momento especialmente significativo porque ilustra bien hasta qué punto doctores y caudillos se habían puesto a trabajar juntos en la solución del problema de la reforma constitucional ${ }^{17}$.

Una vez más, la inestabilidad política frustró las conversaciones. La revolución liderada por Aparicio Saravia estalló el 8 de enero de 1904. Muerto Aparicio, los coroneles Pablo Galarza, en nombre del gobierno, y Basilio Muñoz, en nombre del ejército revolucionario, suscribieron la Paz de Aceguá (24 de setiembre). En el artículo $8^{\circ}$ de este acuerdo puede leerse: "El gobierno incluiría entre los asuntos de las sesiones extraordinarias la reforma de la Constitución, quedando el Poder Legislativo en completa libertad de decretarla o no, y para sancionar en el primer caso, las reformas que juzgase convenientes". La inclusión de la reforma constitucional en la Paz de Aceguá

${ }^{17}$ El Congreso perdió energía rápidamente al menos por dos razones. Por un lado, por razones doctrinarias: algunos (como Jiménez de Aréchaga) preferían acelerar el proceso reformista y convocar lo antes posible una Convención Constituyente; otros (como José Espalter) preferían volver a recorrer el camino de las tres legislaturas sucesivas. Por otro lado, por razones coyunturales: la guerra civil era inminente (Ardao 1973: 435-451).

Araucaria. Revista Iberoamericana de Filosofia, Politica, Humanidades y Relaciones Internacionales, año $21, \mathrm{n}^{\circ} 42$. Segundo semestre de 2019. Pp. 243-276. ISSN 1575-6823 e-ISSN 2340-2199 doi: 10.12795/araucaria.2019.i42.11 
era, por cierto, una concesión al Partido Nacional (era el primer punto de las Bases presentadas por los nacionalistas en las negociaciones de Aceguá). Era, además, una señal de sentido común. El anhelo reformista venía de muy lejos. La reforma constitucional formaba parte de la agenda política desde los primeros años de vida independiente.

El Poder Ejecutivo cumplió rápidamente con el compromiso asumido. Envió el 23 de noviembre de 1904 un proyecto de ley para modificar, siguiendo el procedimiento de las tres legislaturas sucesivas, los artículos 152 a 158 de la Constitución de 1830. Retomaba, en ese sentido, la propuesta plasmada en 1879. Los nacionalistas, en cambio, preferían el camino de autorizar sin más trámite a las cámaras a introducir las enmiendas de fondo (Ardao 1973: 460). La propuesta del Ejecutivo fue aprobada en Diputados pero no fue tratada en el Senado. Encontró, además, amplia resistencia en la prensa nacionalista. En 1906 el senador colorado Carlos Travieso inició nuevamente el proceso reformista: presentó una moción para declarar que el interés general exigía la revisión de la constitución (Ardao 1973: 483).

El 7 de noviembre de 1907 se votó la ley que declaró la necesidad de la reforma. Durante la Legislatura siguiente, el debate sobre el procedimiento reformista fue especialmente intenso en las cámaras. Estaba claro para la mayoría de los legisladores que había que modificar el procedimiento de reforma (los artículos 152 a 158) y luego convocar a una asamblea constituyente. Pero seguía habiendo muchos puntos de vista distintos sobre cómo concretar esto. Algunos temían que la flexibilización del proceso de reforma generara volatilidad institucional. Otros, que la nueva constitución no representara adecuadamente a los distintos actores.

El 3 de noviembre de 1910, se aprobaron 7 fórmulas de modificación de la Sección XII de la carta de 1830. Finalmente, el 28 de agosto de 1912, la legislatura subsiguiente, retomando esas fórmulas, reformó los artículos 152 a 159 de la Constitución de 1830. El nuevo procedimiento también tendría tres pasos. En primer lugar, exigía que se declarara la conveniencia nacional de la reforma por $\operatorname{los} 2 / 3$ de ambas cámaras. En segundo lugar, proponía convocar a una Asamblea Constituyente electa por voto popular. Las enmiendas aprobadas por esta Asamblea, en tercer lugar, deberían ser sometidas a la consideración del cuerpo electoral (Gros Espiell 1988).

En síntesis, y volviendo al marco teórico de Adler. La comunidad de práctica democrática uruguaya tuvo que recorrer un largo y sinuoso camino para encontrar una solución concreta que permitiera reformar la constitución de $1830 \mathrm{sin}$ apartarse de las rígidas normas establecidas en 1830. Caudillos y doctores, por ensayo y error, pragmáticamente, desarrollaron prácticas novedosas y elaboraron el conocimiento reflexivo que permitió alumbrar el camino de la reforma. Los caudillos instalaron muy tempranamente la necesidad 
de la reforma en la agenda política de la república naciente. Protestando, confrontando, pactando y renegociando, fueron elaborando nuevas prácticas (la de los pactos) e instituciones informales (como la coparticipación) que, a la postre, abrieron una brecha para la reforma constitucional. Los doctores, por su parte, también fueron aprendiendo sobre la marcha. Ellos también recorrieron el camino de la experiencia, del ensayo y el error. A la larga, aportaron propuestas concretas respecto a cómo avanzar hacia la reforma. Muchos de ellos insistieron en la importancia de encontrar un mecanismo de reforma que no violara la Constitución de 1830. Otros, especialmente, durante la década del 70', se las ingeniaron para elaborar la solución "mixta" que terminó por viabilizar la elaboración de la nueva constitución. La convocatoria a la CNC refleja, pues, un aspecto de la evolución cognitiva de la naciente democracia uruguaya. Es una expresión institucional del conocimiento de fondo generado pragmáticamente por los dos actores fundamentales de la comunidad de práctica uruguaya.

\section{La ley de 1915: voto secreto y representación proporcional atenuada}

Luego de décadas de discusiones, de intentos inconclusos, de "ensayo y error", los principales actores habían logrado encontrar un procedimiento reformista pragmático que respetaba el espíritu y la letra de la Constitución de 1830. La solución "mixta" que asomó en 1879 precisó tres décadas para terminar de madurar. Sin embargo, para que la CNC pudiera ser convocada todavía quedaba por definirse un aspecto central: el procedimiento de elección de los convencionales. El debate insumió tres años más (desde 1912 a 1915) y estuvo mediado por la publicación en el diario El día de los Apuntes de Batlle y Ordóñez (4 de marzo de 1913). En este texto, el líder colorado manifestó su decisión instalar un Poder Ejecutivo colegiado ${ }^{18}$. Inmediatamente, su propio sector se fracturó en colegialistas y anticolegialistas. La oposición volvió a encresparse. De inmediato, desde la prensa nacionalista, se comparó al líder colorado con el mexicano Porfirio Díaz (Manini Ríos 1973: 99), argumento que ya había sido usado a comienzos de la primera presidencia de Batlle, por Luis Melián Lafinur (1905: 7).

La ley $\mathrm{N}^{\circ} 5332$, que convocó a la elección de convencionales y definió sus reglas, inició su trámite en 1912 y fue sancionada recién en setiembre de 1915. En su artículo 2 puede advertirse todavía el eco del artículo 159 de la

${ }^{18}$ Batlle y Ordóñez, como es sabido, se inspiró en el colegiado suizo. Pero no fue el primero en Uruguay en manejar esta propuesta. En 1903, en el Congreso Revisionista de la Constitución convocado por la Comisión Directiva del Ateneo, el dirigente nacionalista Martín Aguirre ya había manejado esta idea. Lo había hecho con un sentido distinto al de Batlle: pretendía que el colegiado fuera un mecanismo de coparticipación (Ardao 1973: 441, Manini Ríos 1973: 99).

Araucaria. Revista Iberoamericana de Filosofia, Politica, Humanidades y Relaciones Internacionales, año $21, \mathrm{n}^{\circ} 42$. Segundo semestre de 2019. Pp. 243-276. ISSN 1575-6823 e-ISSN 2340-2199 doi: 10.12795/araucaria.2019.i42.11 
constitución de 1830, el que refería a la "Grande Asamblea": establece que en cada Departamento debía elegirse "un número de Convencionales igual al doble de legisladores que le corresponda con arreglo a la actual Ley de Elecciones. Asimismo, la ley consagra la utilización del voto secreto. Además, siguiendo un camino que ya había empezado a ser utilizado en elecciones parlamentarias desde 1898, utilizó un mecanismo electoral que permitía la representación de las minorías. Se llegó a ambas definiciones al cabo de un largo recorrido que hunde sus raíces en la década del setenta del siglo XIX, y que debe mucho a los avances institucionales verificados en Buenos Aires. Este punto no ha sido suficientemente subrayado, hasta la fecha, ni por la historiografía ni por la ciencia política.

\title{
Voto secreto: el problema de las garantías del sufragio
}

Durante las primeras décadas de vida independiente resultó extraordinariamente difícil construir un sistema de reglas que garantizara la libre expresión de las preferencias de la ciudadanía. Según Pivel Devoto, la "historia cívica" del país durante estos años se caracterizó por "el desconocimiento absoluto de las disposiciones legales por quienes debían aplicarlas" y la "intromisión oficial en los comicios", (1994, Tomo I, 282). "El Poder Ejecutivo y sus representantes -agrega Pivel- eran supremos electores" (283). Luego de la Guerra Grande, el reclamo de respeto a las instituciones constituyó uno de los ejes de la crítica a las "divisas" por parte del "fusionismo". Pero le correspondió a la generación principista, que emergió a la vida pública en el primer lustro de la década del setenta, un protagonismo muy especial en la instalación de este reclamo como asunto saliente del debate público y de la agenda política.

En El Siglo, uno de los voceros de los principistas, podía leerse en 1872:

\begin{abstract}
"Digámoslo francamente y sin ambages. No existe en la práctica ninguna de las garantías que aseguran el libre ejercicio del derecho electoral. No hay urnas electorales. La votación se verifica en muchas mesas al aire libre. Todos llevan generalmente su revólver en el bolsillo. Las listas que sirven para votar andan impresas en papeles de distintos colores, de suerte que todos saben qué vota cada ciudadano. (...). Y no hablemos de las influencias que intervienen cuando en la elección se hace sentir la influencia oficial. (...). No nos hagamos ilusiones, mientras no se modifiquen las condiciones materiales del acto de la votación no puede haber nada que se asemeje a la verdadera elección" (citado por Oddone 1956:129).
\end{abstract}

Siguiendo esta lógica, hicieron especial énfasis en el parlamento en el reordenamiento del Registro Cívico. Agustín de Vedia, un protagonista central de los debates institucionales de la época, al poner a consideración de la Cámara su proyecto de reforma sostuvo: "Esta es la base de toda la legislación electoral. 
Dictando una buena ley de Registro Cívico habríamos dado un paso avanzado en el camino de conseguir el verdadero sufragio" (Oddone 1956:132). La ley de Registro Cívico fue sancionada el 11 de diciembre de 1874.

Esta norma fue el primer paso hacia la constitución de un sistema completo de garantías. El segundo paso se verificó muy poco después, durante el gobierno de Latorre. El decreto-ley $\mathrm{N}^{\circ} 1392$ de elecciones dictado el 27 de abril de 1878, entre otras innovaciones, estableció que la lista preferida por el ciudadano debía depositarse en sobre cerrado firmado por el elector. Este sistema, pese a ser un avance en términos de garantías comparado con la modalidad de "voto cantado" anterior, no aseguraba que el voto fuera secreto. De todos modos, era el recomendado por la Cátedra ${ }^{19}$. Precisamente, hacia 1892 el legislador del Partido Nacional, Martín Aguirre, criticaba estas leyes indicando que la "ley del 78 parece hasta calculada para autorizar que el escrutinio modifique o adultere por completo el resultado de los comicios populares", ya que "no establece garantía ninguna para computar el número de boletas o de papeletas de votación que se depositan en las urnas"20.

De este modo, luego de presentar dos proyectos de ley en 1892 y 1894 tendientes a mejorar el Registro Cívico, el 13 de julio de 1908 Aguirre presentó un tercer proyecto de ley que, además de perfeccionar dicho registro, en su artículo $\mathrm{N}^{\circ} 12$ proponía que "el voto en todas las elecciones será completamente secreto, sin que sea permitido poner en la papeleta de votación ni firma ni otro distintivo alguno", a la vez que dichas papeletas serían idénticas entre sí y sin numeración ${ }^{21}$. Respecto a esta propuesta, el diario nacionalista La Democracia publicó un editorial en el que se sostenía que dicho proyecto de ley condensaba la opinión del país ya que se proponía reformar los registros cívicos a los que calificaba como "un depósito de inmundicias electorales" 22 . Sin embargo, el 20 de agosto de 1908 el mismo diario se lamentaba de que el proyecto fuera excluido del período extraordinario de sesiones legislativas, considerando que el gobierno del Presidente Williman se negaba a "cimentar con sólida base el sistema representativo ajustado a la verdad, a la justicia y al derecho"23.

Por tanto, la primera norma que consagró y garantizó el voto secreto fue la ya mencionada Ley $\mathrm{N}^{\circ}$ 5332. Puede leerse en su artículo 38: "El voto en esta elección será completamente secreto, sin que sea permitido poner en la lista de votación ni firma ni otro distintivo alguno". La lentitud en la consagración del voto secreto tiene que ver, en parte con intereses contrapuestos, en parte

\footnotetext{
19 Jiménez de Aréchaga discutió alternativas sobre la publicidad del sufragio en La libertad política: "Este procedimiento es el que existe al presente en nuestro país, establecido por la ley promulgada el 27 de abril de 1878, el que se practica en Inglaterra desde el año 1880 y el que se sigue también la República Argentina y en Baviera". Ver: Jiménez de Aréchaga (1906: 323-326).

${ }^{20}$ Diario de Sesiones de la Cámara de Senadores N58, p. 362.

${ }^{21}$ Diario de Sesiones de la Cámara de Representantes Nº195, p. 718-721.

22 "La palabra de orden" en diario La Democracia, 16/07/1908.

23 "La Reforma Electoral” en diario La Democracia, 20/08/1908.
} 
con debates doctrinarios. El Partido Colorado, que había pasado a controlar el poder desde 1865, evitaba pronunciarse públicamente contra el voto secreto. Pero prefería el statu quo. En palabras de Vanger: "El verdadero riesgo para los colorados era el voto secreto. En teoría, el voto público era 'la característica del verdadero esfuerzo democrático’. En la práctica, (...) el voto público le daba el Gobierno un enorme poder para presionar a los votantes". (2009: 29).

Aun así, en el contexto del debate sobre la ley de elecciones a la $\mathrm{CNC}$, lo aceptaron. Para entender esta decisión hay que tomar en cuenta, por un lado, sus cálculos estratégicos. El batllismo confiaba en ganar. Luego de la derrota, dijo Domingo Arena:

\begin{abstract}
"En los preliminares de la reforma constitucional, fuimos de un optimismo desorbitado en materia de garantías electorales, al punto de que en cualquier otro país donde la gente fuese más positivista, se nos habría tratado de cándidos. Nuestras ansias de hacer las cosas bien hechas, nuestros vivos deseos de que los procedimientos electorales que habrían de emplearse fuesen perfectos, nos llevaron hasta la extravagancia (...). Evidentemente, nosotros en el acto eleccionario del 30 de julio, con el ensayo del voto secreto, sufrimos un principio de derrota. ¡Fue lo totalmente inesperado! Declaro que yo y muchos conmigo nunca esperamos aquel resultado, que debió de haber sido fruto de una serie de cosas raras" (Manini Ríos 1973:175-176).
\end{abstract}

Además, hay que tomar nota de un elemento adicional. El costo político de rechazar esta innovación había crecido significativamente luego de la aprobación en Argentina, el 13 de febrero de 1912, de la Ley Sáenz Peña ${ }^{24}$. Diversos especialistas en la historia electoral sostienen que, hasta la aprobación de la Ley Sáez Peña, el sistema político argentino estaba controlado por una elite que recurría sistemáticamente a la cooptación y al fraude electoral para mantenerse en el poder (Botana 1977, Mustapic 1984). La nueva norma creó condiciones para la democratización en una sociedad con una tradición política "caracterizada por la ausencia de la competencia pacífica por el poder" (Mustapic 1984: 86). Bieda (2010), por su parte, sostiene que esta reforma electoral fue una estrategia para debilitar al roquismo barriendo las prácticas fraudulentas de las viejas cúpulas políticas. Asimismo, reconoce que las garantías electorales aplicadas con esta reforma fueron claves en el crecimiento de la UCR y otros partidos menores, y en la victoria presidencial de Hipólito Yrigoyen en 1916.

Los blancos dieron amplia difusión a esta innovación y la utilizaron para legitimar sus planteos históricos. De hecho, la Juventud del Partido Nacional

${ }^{24}$ El texto original de la norma fue enviado al parlamento por iniciativa del presidente Sáenz Peña y de su Ministro del Interior, Indalecio Gómez, el 6 de noviembre de 1911. Esta ley, que se aplicó por primera vez en abril de 1912 en las elecciones de Santa Fe y Buenos Aires, hizo posible la representación de las minorías (sistema de lista incompleta). Además, consagró el voto obligatorio (artículo 6) y secreto (artículos 39 a 43). Sobre la evolución del proceso político argentino entre 1880 y 1916 ver Botana (1977).

Araucaria. Revista Iberoamericana de Filosofia, Política, Humanidades y Relaciones Internacionales, año $21, \mathrm{n}^{\circ} 42$ Segundo semestre de 2019. Pp. 243-276. ISSN 1575-6823 e-ISSN 2340-2199 doi: 10.12795/araucaria.2019.i42.11 
y diversos medios de prensa organizaron un acto en homenaje a la obra de Roque Sáenz Peña en materia de garantías electorales el 11 de mayo de 1912. Allí participaron oradores del Partido Nacional y del Partido Radical argentino que destacaban la importancia de Sáenz Peña para la efectiva aplicación del sufragio libre en Argentina. Batlle y Ordóñez no argumentó públicamente en contra, pero los batllistas no ocultaron su hostilidad a Sáenz Peña: un grupo de manifestantes interrumpió algunos discursos al grito de “iMuera Argentina!”, “¡Muera Sáenz Peña!” y “;Viva Batlle!”25.

Sáenz Peña se había erigido como símbolo internacional para todos aquellos que promovían mayores libertades y garantías electorales. El costo político de oponerse al voto secreto aumentó. Una vez que los batllistas, después de ser derrotados en la elección de convencionales de 1916, confirmaron que el voto secreto representaba una amenaza a sus intereses, volvieron a oponerse a él. El 9 de agosto de 1916, 56 legisladores batllistas firmaron una declaración contra la propuesta $^{26}$, realizada por el legislador nacionalista Duvimioso Terra, de incorporar el voto secreto a la ley general de elecciones. Escribió Manini Ríos, líder colorado pero antibatllista: "Esta resistencia en las filas batllistas contra el voto secreto se prolongó por mucho tiempo; (...) y motivó la cláusula transitoria $\mathrm{H}$ de la Constitución de 1918 que dispuso que en la primera renovación del tercio del Consejo Nacional de Administración, en 1920, se mantuviera el voto público" (1973: 193).

\section{Representación proporcional: el problema de las garantías para la minoría}

Durante la década del setenta del siglo XIX no solamente se debatió sobre las garantías del sufragio. Además, se instaló por primera vez en la historia nacional, la discusión sobre la representación de las minorías. La “coparticipación", establecida en 1872, era una forma rudimentaria e informal de favorecer la representación de las minorías. Desde ese momento, la representación de las minorías pasó a formar parte de los programas de los "clubes" políticos en los que se agrupaban los "doctores" de la época. Según Pivel Devoto, el Partido Radical ${ }^{27}$ y el Partido Nacional (se refiere a los

\footnotetext{
25 "La reunión del domingo. Mueras a la Argentina y vivas a Batlle" en diario La Democracia, 14/05/1912.

${ }^{26}$ El texto completo de esta declaración puede leerse en Manini Ríos (1973: 190-191)

${ }^{27}$ En 1871, a instancias de personalidades como José Pedro Varela, Carlos María Ramírez, Miguel Herrera y Obes, se crea el Club Radical bajos las banderas "Libertad, igualdad, fraternidad". Son enemigos de la "fusión". Proponen, la "evolución de los partidos" (Pivel Devoto 1994: 164). En 1872 algunos de ellos fundan el Partido Radical. Lo integran, entre otros, José María Castellanos, Miguel Herrera y Obes, Aureliano Rodríguez Larreta, Carlos María Ramírez, Gonzalo Ramírez, Carlos M. de Pena, Eduardo Brito del Pino, Jacobo Varela, Joaquín Baena, José Luis Baena, Carlos Gradin, Rufino Gurméndez (Pivel Devoto 1994: 232). Condenan el exclusivismo, el clásico, "gobernar para mi partido y con mi partido". Proponen reforma constitucional y representación proporcional (Pivel Devoto 1994: 232-233).
} 
respectivos "clubes") proclamaron ese año en sus declaraciones de principios, por primera vez en la historia del país, la idea de la representación proporcional en la elección de representantes.

Un actor muy importante en la diseminación de la representación proporcional fue Agustín de Vedia. Tuvo una actuación política breve pero muy intensa. Entre 1870 y 1872 participó en la Revolución de las Lanzas. En 1873, fundó el periódico La Democracia, donde comentó extensamente el programa de principios del Partido Nacional. Según Pivel Devoto "había tenido a la vista" los debates de la Convención de la Provincia de Buenos Aires (18701873 ) que adoptó la representación proporcional ${ }^{28}$. Fue el primer expositor en Uruguay de los sistemas de John Russel (lista incompleta), de Marshal (voto acumulativo) y de Hare (representación proporcional), adoptado en Dinamarca en 1866 (1994: 332).

Esta referencia conduce directamente, otra vez, a un punto que ya señalamos cuando analizamos el voto secreto: la influencia del debate político argentino en la evolución institucional de Uruguay. La controversia sobre la importancia de la inclusión de las minorías se verificó en ambas orillas del Río de la Plata de modo simultáneo, estimulada por la difusión de los trabajos de J. Borély. El libro La democracia práctica de Luis Vicente Varela ${ }^{29}$, que participó en la Convención mencionada, tuvo un impacto profundo en Uruguay. En palabras de Pivel Devoto:

"La obra del Dr. Luis Varela (...) tuvo una gran influencia en la propaganda que los partidos principistas realizaban a favor de la libertad política. El libro de Varela, que era una prolongación de los debates que habían tenido lugar en Buenos Aires, constituyó desde entonces y por espacio de muchos años, hasta que Justino Jiménez de Aréchaga publicara en 1884 su obra La Libertad Política, la fuente de consulta más completa que circuló entre nosotros sobre los problemas electorales y la que proporcionó elementos de juicio a quienes se ocupaban entonces en la República en el estudio de la expresada legislación" (1994: 346).

Le corresponde, precisamente, a Jiménez de Aréchaga, el mérito histórico de haber redactado en 1876 el primer proyecto orgánico de representación proporcional. Fue publicado en La Democracia (Pivel Devoto 1994: 348352). Desde la Cátedra de Derecho Constitucional, que asumió en 1873, Jiménez de Aréchaga se convirtió en una figura central en la promoción de

28 Ver: "Debates de la Convención constituyente de Buenos Aires, 1870-1873; publicación oficial; hecha bajo la dirección del convencional, Luis V. Varela", publicado por La Tribuna en 1877. Disponible en: https://catalog.hathitrust.org/Record/010452964

${ }^{29}$ La biografía de Luis Vicente Varela, como la Agustín de Vedia, ofrece un testimonio evidente de la imbricación de los procesos políticos de ambos lados del Río de la Plata. Luis Varela nació en Uruguay porque su padre era enemigo de Juan Manuel de Rosas. Algunos datos sobre su trayectoria en: https://www.genealogiafamiliar.net/getperson.php?personID=I80296\&tree=BVCZ

Araucaria. Revista Iberoamericana de Filosofía, Política, Humanidades y Relaciones Internacionales, año $21, \mathrm{n}^{\circ} 42$ Segundo semestre de 2019. Pp. 243-276. ISSN 1575-6823 e-ISSN 2340-2199 doi: 10.12795/araucaria.2019.i42.11 
la representación proporcional. Recogió fragmentos de sus lecciones en la obra La libertad política, publicada en 1884. Dice Pivel: "Tuvo, esta obra, como antes tuviera la de Luis Varela, una influencia extraordinaria en la formación del concepto general acerca de la representación de las minorías y de los sistemas por los cuales podía alcanzarse" (1994: 464). Y agrega: "Después de 1886, cuando comienza la anulación paulatina del caudillismo y el restablecimiento de ciertos aspectos de la libertad política, la idea de representación de las minorías (...) había conquistado el voto de la opinión general, largamente trabajada" (1994: 468).

Prueba de ello es que, en 1887, la Convención del Partido Colorado, resolvió "prestar su voto a la elección de una minoría proporcional de los partidos nacionalista y constitucionalista" (citado por Pivel Devoto 1994: 468). En 1891, el presidente colorado Julio Herrera y Obes planteó la necesidad de concretar una reforma electoral que haga posible la representación de las minorías (Pivel Devoto 1994: 473). Para elaborar la propuesta de reforma el gobierno instaló una comisión de alto nivel político, integrada, entre otros, por Jiménez de Aréchaga. La Comisión recomendó la representación proporcional. Pero el gobierno envió al parlamento un proyecto que contenía solamente recomendaciones sobre el Registro Cívico.

El impulso hacia la representación de las minorías no cesó. En 1897 estalló una nueva insurrección que, como la de Revolución de las Lanzas, culminó en una negociación entre gobierno y oposición. De acuerdo al Pacto de la Cruz, se confió al Partido Nacional la designación de seis Jefaturas Departamentales. Además, el gobierno se comprometió a "prestigiar" la reforma electoral de modo de posibilitar la representación de las minorías (Pivel Devoto 1994: 514515). Las leyes electorales del 29 de abril y 24 de octubre de 1898, finalmente, abrieron el camino hacia la representación de las minorías: asignaron un tercio de las bancas departamentales al partido minoritario en el departamento, siempre que éste alcanzara la cuarta parte de los votantes.

A fines de 1904, luego de vencido el Partido Nacional, el gobierno modificó la legislación electoral perjudicando al partido derrotado (ver Anexo). En setiembre de 1907, mientras José Batlle y Ordóñez estaba en Europa, el presidente José Claudio Williman promovió una nueva modificación corrigiendo parcialmente la ley del "mal tercio" de 1904. En concreto, mientras la ley de 1904 establecía un umbral de acceso al parlamento de 33\%, la nueva ley lo disminuía al 25\% en algunas circunscripciones electorales, facilitando la representación de las minorías. En 1910 promovió una nueva modificación en la misma dirección. Los proyectos de Williman favorecían la representación de los partidos menores, pero aseguraban la mayoría para el Partido Colorado ${ }^{30}$.

\footnotetext{
${ }^{30}$ Tal como señala Diez de Medina (1994: 570), la Historiografía suele no darle el destaque que merece a la obra del Presidente Williman.
}

Araucaria. Revista Iberoamericana de Filosofia, Politica, Humanidades y Relaciones Internacionales, año $21, \mathrm{n}^{\circ} 42$. Segundo semestre de 2019. Pp. 243-276. ISSN 1575-6823 e-ISSN 2340-2199 doi: 10.12795/araucaria.2019.i42.11 
La mayoría del Partido Colorado, y muy especialmente la fracción batllista, tenía reparos hacia la representación proporcional integral. Batlle y Ordóñez admitía que los diputados fueran electos "por el sistema de representación proporcional más perfecto posible”. Pero, el límite de lo posible estaba dado por una cuestión de orden mayor. Los colorados no querían perder el control de la elección presidencial. En 1919, en su recordado Informe a la Convención Colorada "Mi conducta en la Reforma", Batlle y Ordóñez explicó una vez más que solamente estuvo de acuerdo con incorporar la regla de la representación proporcional integral en el parlamento cuando la Asamblea General dejó de tener a su cargo la elección del presidente (Manini Ríos 1973:456). Batlle temía que, así como él fue electo presidente en 1903 con votos de una minoría de legisladores del Partido Nacional encabezada por Eduardo Acevedo Díaz, la representación proporcional pudiera facilitar la situación contraria.

La preferencia del batllismo por el gobierno de partido y la regla de la mayoría iba más allá de los cálculos. Derivaba, en buena medida, de convicciones y creencias muy arraigadas. En primer lugar, de sus principios democráticos. Dijo Batlle: "O somos republicanos, es decir, partidarios de la libertad y del progreso, o no lo somos. En el primer caso, la ley fundamental de las repúblicas es la del acatamiento a la voluntad de las mayorías, y a ella debemos someternos" (en Paredes 1939: 186). En segundo lugar, derivaba de su visión respecto al papel histórico de los dos grandes partidos en pugna. El batllismo se veía a sí mismo como el partido del progreso moral. Creía, asimismo, que el Partido Nacional, su principal adversario" tenía "un carácter "retardatario y reaccionario". Facilitar el incremento de su influencia era equivalente a frenar el progreso del Uruguay ${ }^{31}$.

\section{Representación proporcional en la elección de convencionales}

El batllismo tampoco estaba a favor de la representación proporcional integral para la Convención Constituyente. Los batllistas rechazaron esta solución pese a los esfuerzos del diputado colorado, y ensayista de renombre continental desde la publicación en 1900 de Ariel, José Enrique Rodó (Alonso 2009). En 1911, en el parlamento, Rodó argumentó que la CNC debía ser electa mediante el "alto y noble principio de la representación proporcional". Para Rodó no era justo que el Partido Colorado, conservando "intacta su parte, o sea, la parte del león", concediera "generosamente que, con las sobras, todas las minorías tengan representación”. Rodó insistió en proteger los derechos de los nacionalistas, "la minoría más poderosa". Pero argumentó que también debían estar representadas otras corrientes de opinión. Entre ellas, señalaba "esa

31 Sobre la ideología del batllismo hay una extensa bibliografía. Recomendamos el enfoque de Carlos Real de Azúa (1964: 30-37). Entre los más recientes, remitimos a Carlos Pareja (2016). 
suma de opinión obrera que, (...), forma un partido naciente; “ese núcleo de opinión católica, que ha empezado a tomar ya forma orgánica y militante"; "ese numeroso conjunto de elementos dispersos, y frecuentemente caracterizados, ya por su significación intelectual, ya por la importancia de los intereses gremiales que representan" (1967: 1147-1155).

El desenlace de este debate legislativo se verificó en setiembre de 1915. Durante el extenso proceso legislativo se rechazaron tanto las fórmulas de representación proporcional integral como la regla de "tercios" (Vanger 2009: 29) usada durante los años anteriores. El 15/07/1912 los diputados batllistas Julio María Sosa y Antonio María Rodríguez presentaron un proyecto de ley de elecciones para la CNC que establecía, entre otras novedades, el voto secreto y la representación de $3 /{ }_{5}$ para la mayoría y $2 /{ }_{5}$ para la minoría o minorías. El uso de este novedoso cociente de "quintos" había sido propuesto por otro diputado batllista, Jacobo Varela Acevedo durante debates previos. El proyecto de Sosa y Rodríguez fue aprobado el 05/02/1914 y pasó al Senado, donde se decidió sustituirlo por otro proyecto de Julio María Sosa, Domingo Arena y Juan Paullier. El nuevo proyecto aceptaba y respetaba las bases del original de Sosa y Rodríguez, aunque lo ampliaba y detallaba. Así, se aprobó en el Senado el 10/07/1915 y en Diputados el 01/09/1915, transformándose en la ley № 5332.

Este intrincado trámite parlamentario esconde "pistas" heurísticas de gran valor. En primer lugar, queda claro que, hacia mediados de 1912, los batllistas ya estaban dispuestos a incrementar la participación de la minoría en la CNC. De hecho, fueron legisladores de este sector quienes propusieron el sistema de "quintos". En segundo lugar, la ausencia de Antonio María Rodríguez de la lista de los autores del proyecto finalmente aprobado revela la profunda fractura experimentada por el batllismo luego de la publicación de los Apuntes. Rodríguez fue uno de los líderes colorados que se opuso a la reforma colegialista propuesta por Batlle y Ordóñez. En tercer lugar, no fue el desacuerdo en torno a la regla de elección de convencionales lo que demoró la aprobación del proyecto. Ambas fracciones coloradas, la colegialista y la anticolegialista, coincidían en la regla de los "quintos". Los anticolegialistas demoraron en dar su aprobación a la ley de elecciones para, como explicó mucho después Carlos Manini Ríos ${ }^{32}$, “abrirle expedito al nacionalismo el camino de las urnas", dándole "tiempo suficiente para organizarse y garantías electorales adecuadas" (1973: 134).

Vale la pena destacar, asimismo, que durante el debate parlamentario se retomaron conceptos formulados por Rodó. Dijo el senador colorado anticolegialista Vidal durante la discusión de la Ley de Elección de Convencionales del 21 de mayo de 1915: "Dice Tocqueville en su inmortal obra

${ }^{32}$ Carlos Manini Ríos (1909-1990), abogado y político colorado, era hijo de Pedro Manini Ríos, quien lideró la resistencia al colegiado dentro del Partido Colorado.

Araucaria. Revista Iberoamericana de Filosofia, Politica, Humanidades y Relaciones Internacionales, año $21, \mathrm{n}^{\circ} 42$. Segundo semestre de 2019. Pp. 243-276. ISSN 1575-6823 e-ISSN 2340-2199 doi: 10.12795/araucaria.2019.i42.11 
La democracia en América que: "Si algún día la libertad se pierde en América, será necesario culpar a la omnipotencia de las mayorías que habrán arrojado a la desesperación a las minorías y las habrán forzado a hacer un llamado a la fuerza material. Se verá entonces la anarquía, pero ella se producirá como consecuencia del despotismo". Más adelante agregó:

\begin{abstract}
"Tocqueville cita en esta cuestión a Madison (...): "Es de la mayor importancia en las repúblicas, (...), no solamente defender la sociedad contra la opresión de los que la gobiernan, sino también garantir una parte de la sociedad contra la injusticia de la otra. (...). Si existiese una sociedad en la cual el partido más poderoso estuviese en situación de reunir fácilmente sus fuerzas y de oprimir al más débil se podría considerar que la anarquía reina en esta sociedad, lo mismo que en el estado natural, donde el individuo más débil no tiene ninguna garantía contra la violencia del más fuerte (...). De manera que de acuerdo con todas estas ideas, conviene ir a la reforma de la Constitución, procurando el mayor caudal de opinión para esa obra, en forma que pueda considerarse una verdadera solución nacional. Debo reconocer justamente que los mejoramientos que se han introducido en la ley electoral son uno de los factores que pueden decidir la opinión en el sentido de concurrir a la obra de la reforma".33
\end{abstract}

Pese a las concesiones de los batllistas (voto secreto, cociente de quintos), todavía en 1915 los nacionalistas no estaban convencidos de concurrir a la elección. La Democracia, periódico nacionalista, publicaba:

\begin{abstract}
"dudamos mucho que el partido nacional se resuelva a librar batalla al batllismo reformista al pie de las urnas, con leyes incompletas y bajo el presagio de coacciones y fraudes legitimados o cohonestados por doctrinas tan subversivas e inmorales como las de 'la influencia moral', preconizada por don José Batlle!" [...] "Inútil será que se redacten e impriman leyes y se consignen requisitos y garantías, si esas leyes no han de aplicarse, si esas garantías no han de cumplirse, y si se deja siempre abierta la amplia entrada al impenitente tramoyismo de los oficialismos electorales" ${ }^{34}$.
\end{abstract}

La combinación de los argumentos teóricos a favor de la inclusión de las minorías (que a esa altura tenían, como hemos visto, cuarenta años de circulación en el debate político uruguayo) con la amenaza de los blancos de no concurrir a la elección de la CNC, ayuda a entender por qué el batllismo aceptó entre 1912 y 1915 flexibilizar la regla electoral. A estos dos factores hay que sumarle, otra vez, que los batllistas estaban convencidos de obtener la mayoría, entre otras razones, gracias a sus reformas sociales. En noviembre de 1915 , por ejemplo, fue votada la ley que restringía la jornada laboral a 8 horas, beneficiando a unas " 200.000 personas en Montevideo y ciudades del interior"

${ }^{33}$ Diario de Sesiones del Senado $\mathrm{N}^{\circ} 107$, p. 312.

${ }^{34}$ La Democracia, "El Partido y la Reforma", 21/05/1915.

Araucaria. Revista Iberoamericana de Filosofia, Política, Humanidades y Relaciones Internacionales, año $21, \mathrm{n}^{\circ} 42$. Segundo semestre de 2019. Pp. 243-276. ISSN 1575-6823 e-ISSN 2340-2199 doi: 10.12795/araucaria.2019.i42.11 
(Vanger 2009: 43). De este modo fue posible acordar la ley electoral menos desproporcional de todas las utilizadas desde 1898 en adelante. (Ver anexo).

En síntesis, y volviendo a Adler. La elaboración de las reglas de elección de los convencionales es otro aspecto clave del proceso de evolución cognitiva de la comunidad de práctica democrática uruguaya de la época. La ley de setiembre de 1915 no es otra cosa que la cristalización en el plano institucional del conocimiento de fondo acumulado por caudillos y doctores durante décadas de conflictos y debates, de experimentos y frustraciones. Los caudillos blancos, en particular, tuvieron un papel clave en el impulso al voto secreto y la representación proporcional. Una y otra vez, entre 1870 y 1904, encabezaron revoluciones en nombre del respeto a las minorías. Según la clásica formulación de Robert Dahl en Poliarquía (1989), para que una elite en el poder se resigne a permitir la libre competencia por el poder, el costo de reprimir a la oposición debe ser más alto que el de tolerarla. La insurgencia persistente de los caudillos de oposición elevó desde los tiempos de la Revolución de las Lanzas (18701872) el costo de suprimir a la oposición. Pero, otra vez, correspondió a los doctores la elaboración del conocimiento reflexivo volcado en propuestas concretas de cambios normativos e innovaciones institucionales. Fueron los doctores, desde Agustín de Vedia a Justino Jiménez de Aréchaga, los que hicieron circular los fundamentos teóricos y la legislación comparada sobre sufragio universal y representación proporcional. Es difícil imaginar el camino hacia la democracia en Uruguay sin los caudillos y sus levantamientos. Pero es igualmente difícil pensar la democratización sin la acumulación de aprendizajes en materia electoral desde comienzos de la década del 70 hasta 1915 liderada por la generación principista $\mathrm{y}$, más específicamente, por los catedráticos de Derecho Constitucional ${ }^{35}$.

\section{Conclusiones}

"En el subsuelo de todo nuestro andamiaje institucional republicano se descubre, a poco de rastrear, la huella de una idea o de un principio nutricio inculcado por los liberales del setenta"

Juan Antonio Oddone (1956:166-167)

\footnotetext{
${ }^{35}$ De hecho, como argumentan Buquet y Castellano, la representación proporcional nació junto a la democracia en la elección de convencionales, generando las condiciones de inclusividad y pluralismo necesarias para legitimar a la misma Asamblea Constituyente. Este órgano a su vez consagrará constitucionalmente la representación proporcional y, así, asegurará el carácter competitivo de las elecciones y la legitimidad de sus procedimientos, permitiendo la convivencia pacífica de los partidos y el desarrollo de una democracia de consensos (1996: 108-112). Un excelente panorama general de la adopción de la Representación Proporcional en América Latina desde una óptica teórica diferente a la que hemos propuesto en este artículo puede consultarse en Negretto y Visconti (2018).
} 
La reforma constitucional fue un proceso extenso y controvertido. Todos, desde los jefes militares excluidos del parlamento por la Constitución de 1830 hasta los principales caudillos civiles de principios del siglo XX (José Batlle y Ordóñez y Luis Alberto de Herrera), pasando por las sucesivas generaciones de "doctores" (románticos, fusionistas, principistas, positivistas, constitucionalistas), sabían que reformar la constitución era necesario. Elaborar un camino para hacer posible la innovación institucional dada la complejidad del mecanismo reformista previsto en la Constitución de 1830 y la inestabilidad política que signó el siglo XIX llevó mucho tiempo. Finalmente, se impuso una solución realista y, al mismo tiempo, respetuosa de la formalidad: modificar el procedimiento de reforma siguiendo las reglas de 1830, para poder convocar a una Convención Constituyente.

Los delegados a la Convención fueron electos con una fórmula que incluía voto secreto y una versión atenuada, pero sensiblemente más inclusiva que la "ley de tercios" de 1898 de representación proporcional. Tampoco estas reglas fueron fruto de la improvisación o del azar. Por el contrario, son la expresión de largas discusiones y negociaciones. Representan un auténtico proceso de evolución cognitiva en el sentido de Adler. Los doctores jugaron un papel decisivo en los dos casos: divulgaron información comparada, propusieron argumentos a favor del voto secreto y la representación proporcional en la prensa, en la Cátedra de Derecho Constitucional, en el parlamento y a través de la publicación de obras especializadas como La Libertad Politica, de Justino Jiménez de Aréchaga. En la instalación y circulación de estas ideas jugó un papel muy relevante la experiencia política en la otra orilla del Río de la Plata. Los debates de la Convención de Buenos Aires entre 1870 y 1873, el libro de Luis Vicente Varela, que circuló a partir de su publicación en 1876, y la Ley Sáenz-Peña de 1912 fueron hitos decisivos.

Por cierto, los cálculos estratégicos de los actores dejaron su huella respecto a las reglas electorales a utilizar y en el timing del proceso reformista. Los colorados, a quienes beneficiaba el statu quo, dilataron la reforma constitucional todo lo posible. La aceptaron cuando el costo de la exclusión de los nacionalistas se volvió demasiado alto. Los batllistas no ocultaron su reticencia ante el voto secreto. Aceptaron incorporarlo porque las innovaciones realizadas por el presidente argentino Sáenz-Peña volvieron todavía más políticamente oneroso que antes rechazarlo y cuando calcularon que, gracias a las audaces innovaciones sociales realizadas bajo el liderazgo de Batlle y Ordóñez, tendrían suficiente apoyo popular.

En suma. La lenta y zigzagueante elaboración de las reglas para reformar la primera constitución uruguaya puede ser reconstruida a partir de la teoría de los órdenes sociales de Emanuel Adler. La comunidad de práctica democrática fue aprendiendo (de revolución en revolución, debate 
tras debate) que ningún partido podría excluir al otro. Los caudillos fueron entendiendo que debían pactar entre sí. Los colorados, en el poder desde 1865, fueron admitiendo conceder espacios de poder a los blancos. Los doctores, en particular los de la generación principista, jugaron un papel clave en la instalación de la representación proporcional como mecanismo de inclusión de las minorías. Antes, durante y después de los "liberales del setenta", los doctores contribuyeron a la construcción democrática instalando discusiones, aportando argumentos y preparando fórmulas legislativas. La democracia no es el fruto automático del equilibrio de fuerzas en pugna. Solamente es posible cuando, en la práctica, por "ensayo y error", se genera el conocimiento de fondo que, una vez incorporado en las instituciones, permite distribuir el poder entre los distintos actores. En la dinámica de las instituciones, como en la de las políticas públicas, los actores que son capaces de elaborar soluciones concretas a partir de su conocimiento especializado, juegan un papel decisivo (Campbell 2004: 100-107). La evolución cognitiva transcurre pragmáticamente. Pero, como argumenta Adler, el conocimiento reflexivo juega un papel clave en la elaboración del conocimiento de fondo que alimenta, a su vez, el cambio institucional. La democracia uruguaya es hija de los caudillos populares y de sus aprendizajes. Pero también de los universitarios y del saber "docto". 


\section{Referencias bibliográficas:}

Adler, E. (1997). "Seizing the middle ground: Constructivism in world politics", European Journal of International Relations 3(3), pp. 319-363.

Adler, E y V. Pouliot (editores). (2011). International practices. Cambridge University Press, Cambridge.

Adler, E. (2018). "Democracias en Recesión: Claves Para Pensar Sobre La Estabilidad y Evolución de Órdenes Sociales Internacionales y Regionales", Revista Uruguaya de Ciencia Política, 27(2), pp. 139-154.

Adler, E. (2019). World Ordering. A Social Theory of Cognitive Evolution. Cambridge University Press, Cambridge.

Ardao, A. (1950). Espiritualismo y Positivismo en el Uruguay. Fondo de Cultura Económica, México y Buenos Aires.

Alonso, D. (2009). José Enrique Rodó: una retórica para la democracia. Trilce, Montevideo.

Ardao, M. J. (1973). “Alfredo Vásquez Acevedo: contribución al estudio de su vida y su obra", Revista Histórica, Tomo XLIV, Números 130-132, Museo Histórico Nacional.

Bauzá, F. [1887] (1953). Estudios Constitucionales, Colección Clásicos Uruguayos, Volumen 11, Biblioteca Artigas, Montevideo.

Barbagelata, A. L. (1978). El constitucionalismo uruguayo a mediados del siglo XIX. La Constitución de 1830 y el régimen de la Defensa. Fundación de Cultura Universitaria, Montevideo.

Bieda, T. (2010). "Revolución o re-evolución". Revista de Ciencia Política online, $\mathrm{N}^{\circ} 9$ Edición Especial del Bicentenario de la Revolución de Mayo.

Disponible: https://www.revcienciapolitica.com.ar/num9art2.php

Bobbio, N. (1998). La duda y la elección. Intelectuales y poder en la sociedad contemporánea. Paidós, Barcelona.

Botana, N. (1977). El orden conservador. La política argentina entre 1880 y 1916. Editorial Sudamericana, Buenos Aires.

Bourdieu, P. y L. Wacquant (2005). Una invitación a la sociología reflexiva. Siglo XXI, Buenos Aires.

Buquet, D. y Castellano, E. (1996). "Representación proporcional y democracia en Uruguay". Revista Uruguaya de Ciencia Política, Vol. 8, pp. 107-123.

Buquet, D. (2016). "La construcción de un equilibrio democrático". En: La constituyente de 1916. Fundación de la democracia, Ediciones de la Plaza, Montevideo.

Buquet, D. y Moraes, J. A. (2018). "Construyendo un equilibrio democrático: La reforma constitucional de Uruguay en 1917", Revista Uruguaya de Ciencia Política, Vol. 27, N¹, pp. 19-39. 
Campbell, J. L. (2004). Institutional Change and Globalization. Princeton University Press, Princeton.

Castellanos, A. y Pérez, R. (1981). "El pluralismo. Examen de la experiencia uruguaya (1830-1918)", Serie Investigaciones, N¹4, CLAEH, Montevideo.

Castiglia Barzelli, A. (2004). Principismo y partidos políticos en el Uruguay. Un estudio de las fracciones y partidos “doctorales" en el siglo XIX, Tesis de Ciencia Política, ICP, FCS, UdelaR.

Corbo, D. (2016). "El pacto de los partidos en la construcción de nuestra democracia pluralista y consensual". En: La constituyente de 1916. Fundación de la democracia, Ediciones de la Plaza, Montevideo.

Corbo, D. (2019). Cómo se construyó nuestra democracia 1897-1925. Ediciones de la Plaza, Montevideo.

Dahl, R. (1989). La poliarquía. Participación y oposición, Tecnos, Madrid De la Bandera, M. (1969). La Constitución de 1967, Senado, Montevideo.

Delio, L.M. (2007). Nuevo enfoque sobre los origenes intelectuales del Batllismo. Fundación de Cultura Universitaria, Montevideo.

Diez de Medina, A. (1994). El voto que el alma pronuncia. Historia electoral del Uruguay (1810 - 1910). Fundación Banco de Boston y Fundación de Cultura Universitaria, Montevideo.

Gallardo, J. (2003). "Las ideas republicanas en los orígenes de la democracia uruguaya". Araucaria. Revista Iberoamericana de Filosofía, Política y Humanidades, 5 (9) Disponible en: http://www.redalyc.org/articulo. oa? id=28250902

Gallardo, J. (2018). "Entre la república y la democracia: Justino Jiménez de Aréchaga", Revista Uruguaya de Ciencia Política, Vol. 27, N¹, pp. 6583.

Garcé, A. (2000). "Tres fases en la relación entre intelectuales y poder en Uruguay (1830-1989)" en Técnicos y politica. Saber y poder: encuentros $y$ desencuentros en el Uruguay contemporáneo. Ediciones Trilce, Montevideo.

Gros Espiell, H. (1988). "La evolución constitucional del Uruguay en los últimos setenta años" en Instituto de Investigaciones Jurídicas (comp.) El constitucionalismo en las postrimerías del siglo XX. México D.F: Universidad Nacional Autónoma de México.

Jiménez de Aréchaga, J. [1884] (1906). La libertad política, Editorial Tipográfica Nacional, Montevideo

Lafinur, L. M. (1905). El problema nacional y su solución inmediata, El Siglo Ilustrado, Montevideo. 
Lanzaro, J. (2018). Coordinador del Número Temático "La constitución uruguaya de 1918 y el constitucionalismo latinoamericano", Revista Uruguaya de Ciencia Política, 27 (1).

Martínez, M. C. [1918] 1964. Ante la nueva constitución, Colección Clásicos Uruguayos, Volumen 48, Biblioteca Artigas, Montevideo.

Manini Ríos, C. (1973). Anoche me llamó Batlle, Crónica Política del Uruguay contemporáneo, Montevideo.

Metha, J. (2011). "The Varied Roles of Ideas in Politics". En: D. Béland y R. H. Cox, Ideas and Politics in Social Science Research. Oxford: Oxford University Press, pp. 23-46.

Moraes, J. A. (1995). "Partidos de Ideas en el Siglo XIX. El Partido Constitucional: un marco de análisis preliminar", Cuadernos del CLAEH, 72: 73-95.

Mustapic, A.M. (1984). "Conflictos institucionales durante el primer gobierno radical: 1916-1922”. Desarrollo Económico, Vol. 24, pp. 85-108.

Negretto, G. (2013). Making Constitutions. Presidents, Parties, and Institutional Choice in Latin America. Cambridge: Cambridge University Press.

Negretto, G. L y G. Visconti (2018). "Electoral Reform Under Limited Party Competition: Proportional Representation in Latin America", Latin American Politics and Society, 60(1), pp. 27-51.

Oddone, J. (1956). El principismo del setenta, Instituto de Investigaciones Históricas, Universidad de la República, Montevideo.

Oddone, J. y B. París (2010a). Historia de la Universidad de Montevideo. Tomo I. La Universidad Vieja. 1849-1885, Universidad de la República, Montevideo.

Oddone, J. y B. París (2010b). Historia de la Universidad de Montevideo. Tomo II. La Universidad del militarismo a la crisis. 1885-1958, Universidad de la República, Montevideo.

Pareja, C. (2016). "La encrucijada refundacional de 1916. Las claves de las virtudes y de las inconsistencias de la democracia uruguaya". En: La constituyente de 1916. Fundación de la democracia, Ediciones de la Plaza, Montevideo.

Paredes, C. B. (editor). (1939). Batlle y el colegiado. Publicación del Club Colorado Batllista "José Batlle y Ordóñez" de la 12a Sección Zona 36, Montevideo.

Pérez Antón, R. (1988). "Cuatro antagonismos sucesivos. La concreta instauración de la democracia uruguaya", Revista Uruguaya de Ciencia Política, Vol. 2, pp. 41-59.

Pérez Antón, R. (2017a). "La historia que hicieron los caudillos", en Timoteo Aparicio: Coparticipación y Carta Orgánica, Colección Los Blancos, Volumen V, Ediciones de la Plaza, Montevideo. 
Pérez Antón, R. (2017b). "Los caudillos tras la institucionalización democrática", en Aparicio Saravia: Caudillo de libertades, Colección Los Blancos, Volumen VI, Ediciones de la Plaza, Montevideo.

Pivel Devoto, J. E. [1942] (1994). Historia de los partidos políticos en el Uruguay, Cámara de Representantes, Montevideo.

Real de Azúa, C. (1964). El impulso y su freno, Ediciones de la Banda Oriental, Montevideo.

Rilla, J. (2008). La actualidad del pasado, Debate, Montevideo.

Rodó, J. E. (1967). Obras Completas. Madrid: Aguilar.

Real de Azúa, C. (1969). Legitimidad, apoyo y poder político. Ensayo de tipología. Fundación de Cultura Universitaria, Montevideo.

Vanger,M.(2009).JoséBatlleyOrdóñez, 1915-1917. "Humanizandoelcapitalismo”.

Uruguay y el colegiado, Ediciones de la Banda Oriental, Montevideo.

\section{Anexo}

Leyes electorales y distribución de escaños (1898-1916)

\begin{tabular}{|c|c|c|c|}
\hline & Aprobación & $\begin{array}{c}\mathbf{N}^{\circ} \text { de } \\
\text { Ley }\end{array}$ & Distribución de escaños legislativos por circunscripción \\
\hline 1898 & $22 / 10 / 1898$ & 2563 & $\begin{array}{l}2 / 3 \text { de bancas a la mayoría y } 1 / 3 \text { de bancas a la mi- } \\
\text { noría siempre y cuando alcanzara } 25 \% \text { de los votos. }\end{array}$ \\
\hline 1904 & $27 / 12 / 1904$ & 2920 & $\begin{array}{l}\text { La mayoría se aseguraba } 15 / 22 \text { representantes en Monte- } \\
\text { video, } 5 / 7 \text { en Canelones, } 3 / 4 \text { en Salto, Colonia y Florida, } \\
\text { y } 2 / 3 \text { en el resto de distritos. La minoría obtenía la res- } \\
\text { tante representación si alcanzaba } 33 \% \text { de los votos. }\end{array}$ \\
\hline 1907 & $02 / 09 / 1907$ & 3237 & $\begin{array}{l}\text { La mayoría obtenía } 3 / 4 \text { de representación en Montevi- } \\
\text { deo, Canelones, San José, Florida, Colonia, Salto y Pay- } \\
\text { sandú y } 2 / 3 \text { en el resto de distritos. La minoría lograba el } \\
\text { restante } 1 / 4 \text { o } 1 / 3 \text { si alcanzaba el cuarto o tercio del } \\
\text { total de votos en los distritos que la ley asignaba el cu- } \\
\text { arto o el tercio de representación respectivamente. }\end{array}$ \\
\hline 1910 & $11 / 07 / 1910$ & 3640 & $\begin{array}{l}\text { Las minorías obtenían } 1 / 12 \text { de representantes en Montevi- } \\
\text { deo, } 1 / 8 \text { en Canelones, } 1 / 3 \text { en Rocha, Artigas, Treinta y Tres, } \\
\text { Maldonado, Río Negro y Rivera y } 1 / 4 \text { en el resto de distritos, } \\
\text { si lograban } 1 / 12,1 / 8,1 / 3 \text { o } 1 / 4 \text { de votos respectivamente. }\end{array}$ \\
\hline 1916 & $01 / 09 / 1915$ & 5332 & $\begin{array}{l}3 / 5 \text { de representantes para el partido que obtuviera la mitad } \\
\text { más uno de los votos y } 2 / 5 \text { restantes a la minoría o minorías. }\end{array}$ \\
\hline
\end{tabular}

Fuente: Elaboración propia en base a las leyes electorales de 1898, 1904, 1907, 1910 y 1915. 


\section{Distribución de los 218 escaños de la CNC según diferentes sistemas electorales}

\begin{tabular}{|l|c|c|c|c|c|c|}
\hline Legislación & $\begin{array}{c}\text { Partido } \\
\text { gana- } \\
\text { dor } \\
\text { (PG) }\end{array}$ & $\begin{array}{c}\text { Primera } \\
\text { minoría } \\
\text { (PM) }\end{array}$ & $\begin{array}{c}\text { Otras } \\
\text { minorías } \\
(\mathbf{O M})\end{array}$ & $\begin{array}{c}\text { PG - } \\
\text { PM }\end{array}$ & $\begin{array}{c}\text { PG - (PM } \\
\text { y OM) }\end{array}$ & $\begin{array}{c}\text { Índice } \\
\text { de Prop. } \\
\text { Gallagher }\end{array}$ \\
\hline 1898 & 121 & 97 & - & 24 & 24 & 9,51 \\
\hline 1904 & 127 & 91 & - & 36 & 36 & 10,46 \\
\hline 1907 & 120 & 98 & - & 22 & 22 & 9,42 \\
\hline 1910 & 123 & 91 & 4 & 32 & 28 & 8,67 \\
\hline 1916 (Real) & 105 & 85 & 28 & 20 & -8 & 1,30 \\
\hline 1916 (D’Hont) & 110 & 89 & 19 & 21 & 2 & 3,07 \\
\hline 1916 (Hare) & 103 & 88 & 27 & 15 & -12 & 0,39 \\
\hline 1916 (RRP- & 103 & 88 & 27 & 15 & -12 & - \\
\hline PII) & & & & & & \\
\hline
\end{tabular}

Fuente: Elaboración propia en base a las leyes electorales de 1898, 1904, 1907, 1910, 1915, sistema D’Hont, Hare y Representación Proporcional Integral de acuerdo a los resultados electorales de la elección de convencional de 1916. El Índice Gallagher varía entre 0 y 100.

Esta simulación muestra la evolución de la desproporcionalidad desde la primera regla aprobada en 1898, luego del Pacto de la Cruz, y 1916. 
Evolución del Î́ndice de Proporcionalidad de Gallagher (1898-1916)

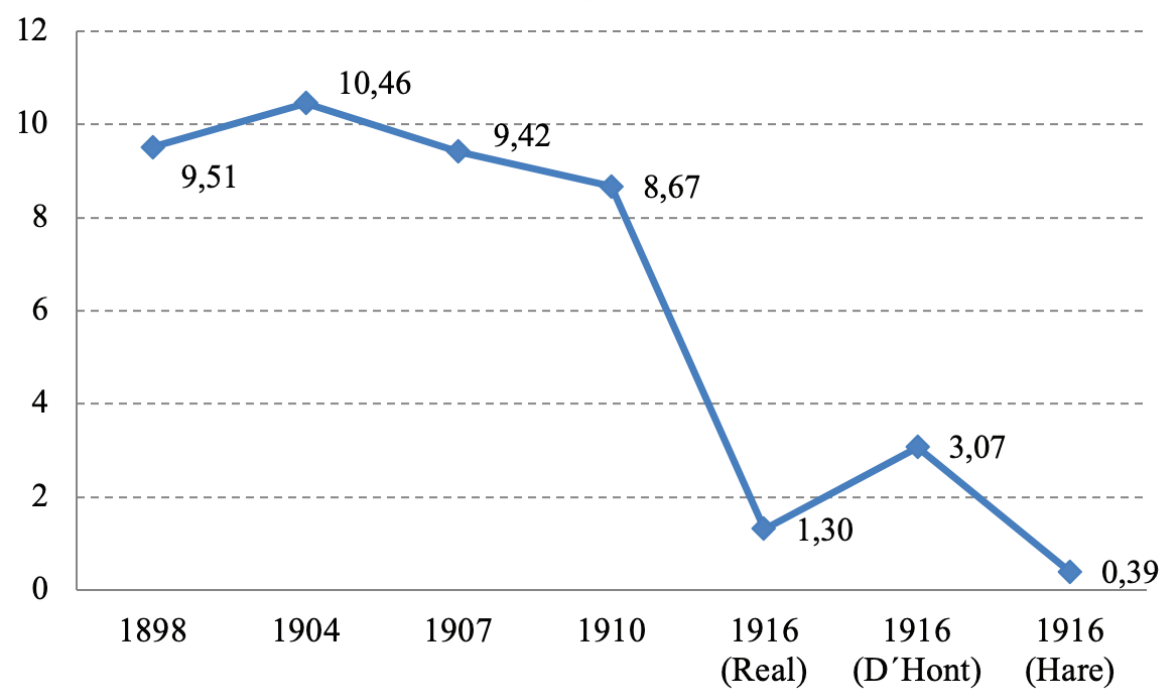

Fuente: Elaboración propia

En el gráfico se ilustra más claramente esta dinámica. Las leyes utilizadas entre 1898 y 1910 generaban una desproporcionalidad mayor que la aplicada en la elección del 30 de julio de 1916. Nótese también que el método D’Hont, tan resistido por el batllismo, lo hubiera beneficiado levemente. 
Línea de tiempo: hitos políticos y avances en materia de garantías electorales

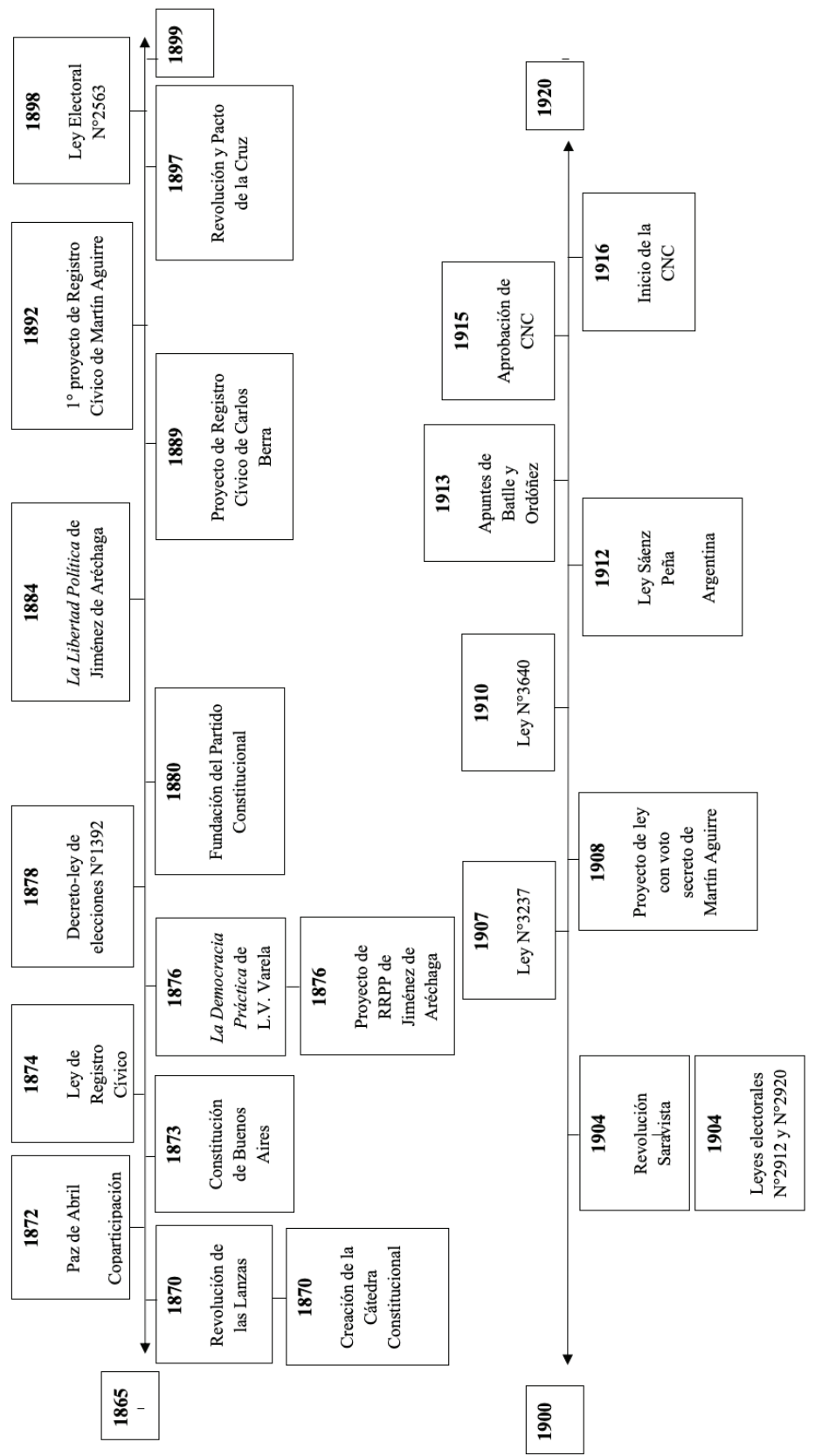

